\title{
Synthesis of $\mathbf{O}$-Glycosides 1,3-Diynes
}

\section{Túlio R. Couto , Juliano C. R. Freitas, João R. Freitas Filho, Silvia R. C. P. Andrade, Ivani Malvestiti and Paulo $\mathrm{H}$. Menezes}

\author{
Departamento de Química Fundamental, CCEN, UFPE, 50670-901, Recife-PE, Brasil
}

"tuliocouto@gmail.com

Keywords: O-glycosidation, O-glycoside dimers, homocoupling

\section{INTRODUCTION}

The unique properties of poliynes and acetylenic arrays continue to receive attention and increased research interest. ${ }^{1}$ In addition to their unusual electrical and optical properties, they are encountered in numerous natural products and display a wide range of potential applications in both biology and material sciences. Consequently, research into the synthesis of well-defined poliynes continues to expand.

The most common synthetic method for the assembly of poliynes involves bond formation between two acetylenes via oxidative coupling. The major challenge in the preparation of this class of compounds is the tolerance to sensitive functional groups. Consequently, the development of alternative methods for the preparation of highly functionalized poliynes is of the great interest.

\section{RESULTS AND DISCUSSION}

Tellurium tetrachloride was used as the Lewis acid choice to promote the $O$-glycosylation of glycal 1 to yield 2,3-unsaturated-O-glycosides $2{ }^{2}$ The results are depicted in Table 1.

Table 1. Synthesis of 2,3-unsaturated O-glycosides, $\mathbf{2}^{\mathrm{a}}$

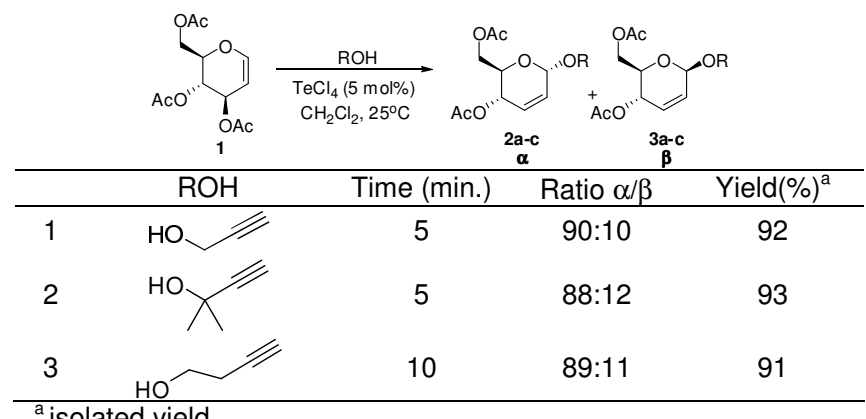

In all cases the reaction proceeded smoothly leading to the complete conversion of $\mathbf{1}$ into the corresponding 2,3-unsaturated $O$-glycoside 2 in high yield and with good $\alpha$-selectivity.

Next, we tested the homocoupling of alkynes 2 promoted by $\mathrm{NiCl}_{2} \cdot 6 \mathrm{H}_{2} \mathrm{O}$ and $\mathrm{Cul}$ under aerobic conditions. ${ }^{3}$ The results are summarized in Table 2.
Table 2. $\mathrm{NiCl}_{2} \cdot 6 \mathrm{H}_{2} \mathrm{O}$ and $\mathrm{Cul}$ promoted synthesis of diynes 4a-c

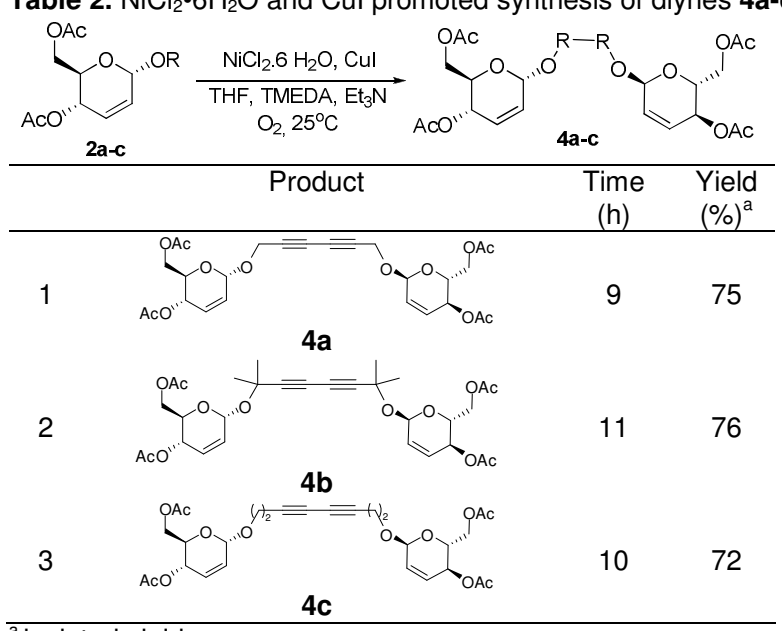

${ }^{\mathrm{a}}$ isolated yield

The obtained compounds could be used in the synthesis of aromatic residues circumscribed by pendant sugar haptens. Although these oligomers afford only weak biological activity relative to their native glucan counterparts, nevertheless, such sugar cluster provides unique environments for hostguest chemistry of amphipathic molecules.

\section{CONCLUSION}

In summary, we have demonstrated the use of a catalytic amount $\mathrm{NiCl}_{2} \cdot 6 \mathrm{H}_{2} \mathrm{O}$ and $\mathrm{Cul}$ under aerobic conditions to promote the synthesis of diynes. The functionalized glycosides were synthesized under mild conditions, excellent yields and good $\alpha$ anomeric selectivity.

\section{ACKNOWLEDGEMENTS}

The authors gratefully acknowledge CNPq, CAPES, FACEPE and INCT-INAMI for the financial support.

\section{REFERENCES}

Siemsen, P.; Livingston, R. C.; Diederich, F. Angew. Chem., Int. Ed. 2000, 39, 2632

Oliveira, J. M. ; Palmeira, D. J. ; Comasseto, J. V. ; Menezes. P. H. J. Braz. Chem. Soc. 2010, 21, 362-366.

${ }^{3}$ Yin, W.; He, C.; Chen, M.; Zhen, M.; Zhang, H.; Lei, A. Org. Lett. 2009 , $11,709$. 